\title{
The Theory of Actual Employee and De Facto Authority and Its Applicability in Iraq
}

\author{
Ali Salman Jamil \\ Department of Law, AlMaarif University College, Anbar, Iraq \\ ali.jameel@uoa.edu.iq
}

\begin{abstract}
:
The research showed that the French Council of State relied in resolving the conflict between the authority and the citizen on the principles of the Declaration of Human and Citizen Rights as a basis for the principle of legality. He only had them. They are abstract general rules that clarify the basis of the relationship between the citizen and the state, including his rights and duties. The council applied its rules regarding the rulings it issued, whether for the authority or against it. The authority has caved in to that. He also showed that it is impermissible to differentiate between protecting rights in normal and exceptional circumstances. The state is responsible for securing these rights in all circumstances. This is why the board invented the actual employee theory. The basic principles on which the actual employee theory was based have also been studied. The theory is not an exception to the principle of legality, but rather a real application of it. In a state that has taken upon itself to ensure that people enjoy the rights and freedoms stipulated in the constitution. It also clarified that the employee's organizational relationship with the state requires it to respect his rights stipulated in the law in return for his commitment to his duties that oblige him to apply the law as abstract general rules without bias and deviation. Therefore, it has the right to punish him according to the law. In exchange for his right to appeal the decision to impose the punishment. The judiciary's decision to cancel the dismissal or dismissal decision obliges the administration to return it to the same legal position. Unless that results in corruption, then you must return him to a center parallel to the first. Without causing him physical or moral harm. The research also showed that what happened in Iraq was a barbaric invasion that was not based on any justification. It expressly contradicts international legality. It has resulted in the abolition of all legitimate institutions of the state and the handing over of power to organizations that have proven practical reality that they are gangs of thieves whose aim is to destroy the state and to violate all prohibited acts. It issued laws that grant themselves privileges and rights that are inconsistent with the principle of legality. And decisions were issued that contradict the public interest. Therefore, citizens and employees should be granted the right to appeal all laws and decisions issued when real authority is established in Iraq. Return all stolen money and stolen rights.
\end{abstract}

\section{Keywords: Actual Employee; Legality Principle; Administrative Law; Exceptional Circumstances; Ordinary Circumstances.}

Crossref doi https://doi.org/10.51345/.v31i2.259.g178 


\section{نظرية الموظف الفعلي وسلطة الامر الواقع ومدى انطباقها في العراق \\ د. علي سلم|ن جميل \\ قسم القانون، كلية المعارف الجامعة، الأنبار، العراق \\ ali.jameel@uoa.edu.iq}

\section{ملخص البـحث}

بين البحث ان بجلس الدولة الفرنسي استند في حسم النزاع بين السلطة والمواطن الم مبادئ اعلان حقوق الانسان والمواطن باعتبارها اساساً لمبدأ المثروعية. فلم يكن لديه سواها. وهي قواعد عامة بجردة تبين اسس العلاقة بين المواطن والدولة بها له من حقوق وما عليه من واجبات. فكان المجلس يطبق قواعده فيا يصدره من احكام سواء للسلطة او عليها. وقد رضخت السلطة لذلك. كما بين عدم جواز التفريق بين حماية الحقوق في الظروف العادية والظروف الاستثنائية. اذ ان الدولة مسؤولة عن تأمين هذه الحقوق في كل الظروف وهذا هو السبب في ابتداع المجلس لنظرية الموظف الفعلي. كما تمت دراسة المبادئ الاساسية التي استندت عليها نظرية الموظف الفعلي. فالنظرية ليست استثناء على مبدأ المشروعية وانما هي تطبيق حقيقي له. في دولة اخذت على عاتقها ضمان تمتع الناس بالحقوق والحريات المنصوص عليها في الدستور. كما اوضحت ان العلاقة التنظيمية للموظف بالدولة تفرض عليها احترام حقوقه المنصوص عليها في القانون مقابل التزامه بواجباته التي تلزمه بتطبيق القانون بوصفه قواعد عامة بجردة دون تحيز وانحر اف. ولذلك فان لها الحق في معاقبته وفقا للقانون. مقابل حقه في الطعن بقرار فرض العقوبة. وان قرار القضاء بإلغاء قرار الفصل او العزل يلزم الادارة بإعادته الى المركز القانوني ذاته. الا اذا ترتب على ذلك مفسدة. فتلنزم بإعادته الى مركز مواز للمركز الاول. دون ان يلحقه ضرر مادي او معنوي. كما بين البحث ان ما حصل في العراق هو غزو همجي ويتنافى صراحة مع المثروعية الدولية. وقد نتج عنه الغاء لكل المؤسسات الثرعية للدولة وتسليم السلطة الم تنظيات. فأصدرت قوانين تمنح لنفسها امتيازات وحقوق تتنافى مع مبدأ المثروعية. واصدرت قرارات تنافي المصلحة العامة. ولذلك ينبغي منح المواطنين والموظفين الحق في الطعن بكل ما صدر من قوانين وقرارات عندما تقوم في العراق سلطة حقيقية. تعيد كل الاموال المنهوبة والحقوق المسلوبة.

الكلمات المفتاحية: الموظف الفعلي، مبدأ المشروعية، القانون الإداري، الظروف الاستثنائية، الظروف الاعتيادية. Crossref doi) https://doi.org/10.51345/.v31i2.259.g178 
المقدمة:

\section{أهميلة البحث :}

تعد نظرية الموظف الفعلي من جملة النظريات التي ابتدعها بجلس الدولة الفرنسي لمعالجة القرارات التي تصدر من شخص لا يتمتع بسلطة اصدار قرار. اما لأنه ليس له صفة الموظف العام. واما لان قرار تعيينه غير

مشروع.

ويستمد الموضوع اهميته من الواقع الحالي في العراق ، فقد تمت ازاحة عشرات الالاف من الموظفين الذين يشغلون وظائفهم بالمخالفة لأحكام قو انين الخدمة المدنية والعسكرية وغيرها من قوانين الخدمة . وبالمخالفة لأحكام قانون انضباط موظفي الدولة والقطاع العام وغيره من القوانين. وقد تم استبدالهم بأشخاص لا تتو افر لديهم المؤهلات وفقا للمعايير القانونية لشغل الوظائف المدنية والعسكرية التي تم تعيينهم بها ، كما ان القرار ات صدرت من اشخاص او جهات غير مختصة قانونا بذلك، فنتجت عنه اضراراً كبيرة لحقت بالمصلحة العامة. وقد حصل ذلك خلال بداية الدوام بعد الاحتلال عام ب. ..r. فصدرت تلك القرارات في ظرف استثنائي كانت فيه الدولة تحت ادارة الاحتلال ولا يمكن لاحد الاعتر اض عليها . وبعد تشكيل سلطات الدولة في العراق خلال عام ه · ب استمر الحال في عدم احترام قوانين الخدمة و القوانين المنظمة للوظيفة العامة وقيام الاحزاب المتنفذة بإصدار مئات الآلاف من قرارات الازاحة والتعيين والنقل خارج الضوابط المحددة في القوانين. واعتبرت ان الوظيفة العامة غنيمة توزعها على اتباعها دون ضو ابط، وليس باعتبارها خدمة اجتماعية وامانة مقدسة.

\section{اشكالية البححث:}

لاشك في ان الموظفين الذين هضمت حقوقهم جبرا عنهم في ظل ظرف استثنائي لم يكن بإمكانهم دفعه ولم تكن لهم اي جهة يعترضون لديها. يعد حقهم في الاعتراض محفوظ عندما توجد جهة تنصفهم ، وتعيد لهم حقوقهم المشروعة وفقاً للقانون ـ سواء الاحياء منهم والاموات ، اذيحق لورثنهم المطالبة بحقوقهم المشروعة وتعويضهم عن الاضرار المادية والمعنوية . 
واتمنى على الباحثين من رجال القانون الاهتمام بدراسة هذا الموضوع وبيان وجهات نظرهم فيه ـ نظراً لأنه يهم مئات الاف المواطنين في العراق .

\section{منهجيـة البـحث:}

لقد بينت ان مجلس الدولة الفرنسي الذي ابتدع نظرية الموظف الفعلي. كان هدفه تطبيق مبدأ المشروعية من جهة ومن جهة اخرى حماية المصلحة العامة وحماية حقوق الافراد حسني النية. ونحن اليوم نريد حماية حقوق مئات الالاف من الموظفين بتطبيق مبدأ المشروعية، الذي وجد من اجل حماية الحقوق والحريات التي تكفلها كل الدول بالنص عليها في دساتيرها، ومنها دولة العراق.

\section{المطلب الاول : المبادئ التي استوحيت فِ ابتداع نظرية الموظف الفعلي} لم يكن لدى بجلس الدولة الفرنسي قانون يطبقه على ما يعرض عليه من شكاوى ، لأنه تشكيل جديد ابتدعته الثورة الفرنسية لتقديم المشورة الى رئيس الدولة بشأن الدعاوى الادارية التي تقام ضد الادارة ـ وذلك لمنع المحاكم العادية من نظرها تطبيقاً لمبدأ الفصل بين السلطات الذي قرره دستور الثورة ـ ونص فيه على منع القضاء من استدعاء اي موظف بشأن دعوى تتعلق بعمله الاداري . وكان رئيس الدولة يميل القضايا المى المجلس ليقترح عليه الحكم القانوني لها. فان صدقه مضى وان اعترض يعاد المى المجلس لاقتراح غيره ـ ولكن لم يجصل أن اعترض رئيس الدولة على حكم للمجلس، وذلك لان اعضاء المجلس من فقهاء القانون ومنظريه. وسنبين المبادئ التي استلهمها المجلس من اعلان حقوق الانسان،

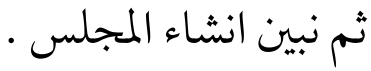

\section{الفرع الأول: مبادئ الإعلان الفرنسي لحقوق الإنسان والمواطن}

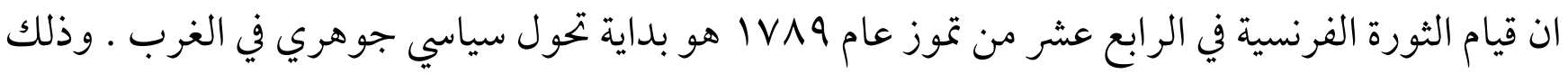
بإقرارها مبادئ الاعلان الفرنسي لحقوق الانسان والمواطن ليكون مرشداً للسلطة في التعامل مع الشعب .

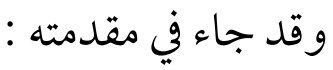


ان جهل حقوق الانسان او نسيانها او ازدراءها هي الاسباب الوحيدة للمصائب العامة ولفساد الحكومات. لذلك جاءت هذه الوثيقة لتكون حاضرة وبصورة دائمة امام اعضاء المجتمع لتذكيرهم بالاستمرار بحقوقهم وواجباتهم كي تكون اعمال السلطتين التشريعية والتنفيذية بمقارنتها في كل لحظة مع هدف كل مؤسسة سياسية اكثر انضباطاً . ولأجل ان ترتكز مطالب المواطنين على مبادئ بسيطة لا خلاف حولها ، تتمحور دائما

$$
\text { وقد ولد احترام الدستور وسعادة المجتمع. }
$$

ان هدف كل تجمع سياسي هو الحفاظ على حقوق الانسان الطبيعية غير القابلة للتقادم (م/ Y) . و وان لا حدود لملمارسة الحقوق الطبيعية الا تلك التي تؤمن للأعضاء الاخرين في المجتمع التمتع بالحقوق نفسها والتي لا يمكن تحديدها الا بقانون (م/ ع ) . وان كل ما لا يحرمه القانون لا يمكن منعه ولا يمكن اجبار احد على فعل ما لا يأمر به القانون (م/ ه) ـ وان القانون هو تعبير عن الارادة العامة ولكل المواطنين الحق في الاسهام المباشر او بو اسطة مثثليم في صياغته وان جميع المو اطنين متساوون وهم مقبولون في كل المناصب والوظائف العامة كل حسب كفاءته ودون تمييز سوى على ما ارتكز على فضائلهم ومو اهبهم (م/7 ) . ويجب الامتناع عن ازعاج اي انسان بسبب آرائه حتى الدينية مادام التعبير عنها لا يعكر النظام العام المرتكز على القانون (م/ • ( ) . وان ضمان حقوق الانسان والمواطن يستدعي وجود قوة عامة مشكلة لصالح الجميع وليس للمنفعة الخاصة لأولئك الذين اوكلت اليهم (م/ r I ) ـ ولإنفاق على القوة العامة وتأمين مصاريف الادارة لابد من فرض ضريبة مشتر كة يجب توزيعها على المو اطنين بالتساوي تبعا لإمكاناتهم (م/ با ) . و ان للهيئة الاجتماعية الحق في ان تحاسب كل موظف عام مها كانت ادارته ويدلاً عنها (م/ 1 ). وكل مجتمع لا تكون فيه ضمانة الحقوق مؤمنة ولافصل السلطات محدد، هو مجتمع لا دستور له اطلاقا (م/ 7 ( ) . 


\section{الفرع الثاني: إنشاء مجلس الدولة}

من وحي تلك المبادئ تم تأسيس مجلس الدولة ليكون مستشاراً لرئيس الدولة في حمل السلطة التنفيذية على الالتزام بمبدأ الفصل بين السلطات ومحاسبة من يخرقه ـ واحترام الحقوق المنصوص عليها في الدستور وضمان تمتع المو اطنين بها .

ومن الاحكام والمبادئ التي قررها المجلس طوال مسيرته منذ تأسيسه سنة • IV9 والمى يومنا هذا نجد انه كان يلتزم بحماية حقوق الانسان والمواطن ويوازن بين المصلحة العامة وبين ضمان تمتع الفرد بحقوقه التي كفلها له القانون .

غير انه لما عادت الملكية الى فرنسا وعلم بنية الملك حل المجلس تحاشى الاصطدام به ـ فابتدع نظرية اعحال السيادة مفرقا بين اعمال الادارة واعمال الحكومة ليحتج بعدم اختصاصه بأعال الحكومة لان الرقابة عليها تدخل ضمن اختصاص البرلمان ـ وقد اعتبر فقهاء القانون تلك خطيئة كبرى في تاريخ المجلس بو صفه حامي الشرعية ـ وقد عمل المجلس بعد ان اعترف له بالصفة القضائية وبصلاحية اصدار احكام باتة .على تقليص نطاق الاعمال التي تشملها هذه النظرية . وقد اثبت المجلس انه كان اكثر جرأة وثباتاً في الدفاع عن الحقوق والحريات ضد تعسف الادارة وتجاوزاتها، مستنداً المى مبادئ اعلان حقوق الانسان والمواطن • وقد اثمرت منجزاته خلال ثمان عقود كمستشار لرئيس الدولة المى وضع ما عرف بمبادئ واحكام القانون الاداري الذي اصبحت له الهيمنة بمبادئه المتميزة على الساحة القانونية في الدولة الحديثة.

وتعد نظرية الموظف الفعلي احدى منجزاته المبكرة ، لحماية حقوق الافراد حسني النية من اخطاء الادارة . ومراعاة مبدأ سير المر افق العامة بانتظام واضطراد في ظل الظروف العادية والاستثائية . 


\section{المطلب الثاني: نظريـة الموظف الفعلي وآثارها} سنتاول الموضوع في فرعين ، تعريف الموظف الفعلي وظروف وجوده ـ والاثار التي تترتب على تطبيق نظرية

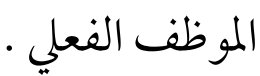

\section{الفرع الأول : تعريف الموظف الفعلي وظروف وجوده}

الموظف الفعلي: هو موظف الامر الواقع وهو من يتولى الوظيفة دون صدور قرار اداري من الجهة المختصة بتعيينه في وظيفته ـ واما لصدور قرار اداري بتعيينه ، ولكن القرار مشوب بعيب يجعله غير صحيح · هذا الشخص رغم انه لا اختصاص له بصفة عامة في اتخاذ قرار معين ولكنه مارس صلاحيات الوظيفة التي شغلها فعلاً. فقد اعتبره الفقهاء كما لو كان مزود بصلاحيات الوظيفة قانوناً . فمن غير المتصور ان يطلب منه الاشخاص الذين يراجعون لإنجاز معاملاتهم ابراز سند وظيفته ـ. ولذلك يرى البعض ان تطبيق النظرية يكون في الظروف الاستثنائية ويكون في الظروف العادية على السواء(1). مثال في الظروف الاستثائية : في حالة غياب الحكومة الشرعية ، كما حصل في فرنسا خلال الحرب العالمية الاولى ، حينما تصدى جماعة من الافراد العاديين لأععال المجلس البلدي في بعض المقاطعات ـ وفي مصر اثناء العدوان الثلاثي عام 1907 عندما تولى ادارة المجلس البلدي في غزة بسبب غياب السلطة اثناء الاحتلال

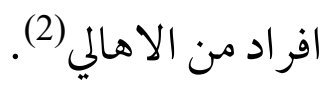
والمثال في الظروف العادية : صدور قرارات ادارية بواسطة فرد تمتع بصفة الموظف العام استناداً المى قرار تعيين غير مشروع ثم تقرر سحبه او الغائه بعد مدة من الزمن • وفي حالة السحب او الالغاء يصبح قرار تعيين الموظف كأن لم يكن في اي وقت من الاوقات ـ في حين انه قد زاول كل سلطات الوظيفة ، ولذلك قضت محكمة النقض الفرنسية في قرارها الصادر في V آب عام ؟1N1 بصحة عقود زواج ابرمها احد العمد بواسطة مساعد له في دار العمودية بالمخالفة للقانون ـ مستندة في ذلك الى فكرة الموظف الفعلي (3). الا ان بجلس الدولة المصري قد اخذ بنظرية الموظف الفعلي في الظروف الاستثنائية دون الظروف العادية. حيث قررت المحكمة الادارية العليا(4)، في حكم لما صدر في ^Y حزيران سنة ع79 19 بأن: (نظرية الموظف 
الفعلي لا تقوم الا في الاحوال الاستثنئية البحتة تحت الحاح الحاجة المى الاستعانة بمن ينهضون بتسيير دولاب العمل في بعض الوظائف ضماناً لانتظام سير المرافق العامة وحرصا على تأدية خدماتها للمنتفعين باطر اد ودون توقف) . وقد تعرض مسلك المحكمة السابق للنقد(5). لان فكرة النظرية هي حماية الغير حسني النية ، وهو هدف واحد سو اء في الظروف العادية او في الظروف الاستثائية ـ ثم ان الثقة الواجب تو افرها في تصرفات الادارة ، وما تتمتع به من قرينة الشرعية تستوجب تطبيق هذه النظرية لكي لا تتزعزع ثقة الافراد في قرارات الادارة بها

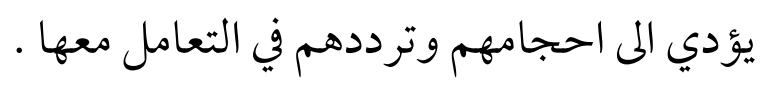
ولذلك عدلت المحكمة الادارية العليا عن اتجاهها السابق(6). في حكم ها بتاريخ وب أيار سنة ع · • ب الذي قالت فيه بانه (قد بات مستقراً ان للمواطن ان يثق ثقة مشروعة في التصرفات التي تجريها الادارة مادامت هذه التصرفات ليست متعارضة بحسب الظاهر وعلى نحو يدركه المو اطن العادي مع الدستور والقانون أو لم تقم على غش من جانبه ويقع على جهة الإدارة اثبات هذا الغش • ويبنى على ذلك ان يكون للفرد في اطار الشرعية وسيادة القانون وفقا لأصول الادارة السليمة ان يثق في القرار الصادر من الجهة الادارية او في الاجراءات السابقة لصدوره و المكونة لوجوده وان يتعامل معها على اساسه وان يتمسك بمركزه القانوني الذي خلقه ذلك القرار او تلك الاجراءات ، حتى لو كان التصرف من اختصاص جهة ادارية اخرى ، ومن ثم يكون للمو اطن ان يرتب اوضاعه على ما اجرته الجههة التنفيذية من تعاقد ، او ما اصدرته من تخصيص، او ما عملته من تصرفات ويجب عليها احترام المركز الذاتي الذي اكتسبه المو اطن ، ولا يجوز لها ان تتسلب من تصرفاتها للنيل من المركز القانوني مستندة إلى عيب شاب تصرفها، او سبب للكشف عن تقصيرها في سلطة الاشراف والرقابة على تصرفات مرؤوسيها ، كما ان خروج احد تابعيها عن اختصاصه الوظيفي يجعله محلا للمساءلة الادارية ولا يجوز ان يضار المواطن من جراء ذلك ، وذلك ماية للمركز القانوني والوضع الظاهر الذي يجب احترامه، واعمالاً للاستقرار الواجب للعلاقات مع جهات الادارة ، ولعدم زعزعة الثقة المشروعة للأفراد في تصرفات الادارة العامة وهي في مستو اها الاعلى التي يجب ان يتعامل معها والتي حازت ثقة المتعاملين). 


\section{الفرع الثاني : الاثار التي تترتب على تطبيق نظرية الموظف الفعلي.}

يترتب على تطبيق النظرية اعتبار كل القرارات التي اصدرها الموظف الفعلي صحيحة. بشرط ان يكون اصحاب الشأن حسني النية ، وان يكون لديهم من الاعتقاد ما يدفعهم المى عدم الشك في صحة تعيين الموظف. وفي ذلك يقول بجلس الدولة الفرنسي)(7): (ان عدم شرعية انشاء وظيفة السكرتير العام المساعد ، لا تمس شرعية القرارات التي كان قد اتخذها). وفي حكم حديث له صدر في r ا من كانون الاول سنة V. . . قال فيه(8): (ان التصرفات والاحكام التي قام بها القاضي الذي الغي قرار تعيينه تعتبر صحيحة لإزالة الضرر الذي يقع على مرفق القضاء لولم يتم الاعتراف

بناءُ على ما تقدم فان الرجعية التي يجب ان تطبق في حالات إلغاء القرارات غير المشروعة تبدو غير مقبولة بالنسبة للقرارات التي يصدرها الموظف الفعلي ولا تتفق مع المنطق ، فلو سحبت الادارة قرار تعيين او ترقية موظف اوحكم بإلغائه ، فان الاثر الرجعي للسحب او الالغاء يقتضي اعتبار القرارات الصادرة منه معدومة لصدورها من غير غختص، لاسيا ان عيب عدم الاختصاص يتعلق بالنظام العام، ومع ذلك فان مصلحة

المجتمع تقتضي ابقاءها منتجة لآثارها وتطبيقا لمبدأ العدالة، في الحدود التي تقتضيها نظرية الموظف الفعلي (9). بل ذهب البعض (10)، المى القول بان الموظف في مثل هذه الامور يكون قد تولى الوظيفة وفق سند سليم ـ وكل ما في الامر انه كان يحارس اختصاصاً ظاهرياً تعذر على الغير العلم بعدم توافر الولاية اللازمة للقيام بهذه التصرفات، ومن ثم فان قراره يكون وفقاً لتطبيق فكرة الاختصاص الظاهر وليس لفكرة الموظف الفعلي. ويرى البعض (11) انه من الصعب التكهن من جهة الغير بان تولية الشخص الذي يتعامل معه غير مشروعة. وتطبيقا لذلك قضت المحكمة الدستورية العليا(12، في حكمها الصادر بتاريخ 19 مايس سنة • 199 بان: (عدم دستورية المادة الخامسة مكرر من القانون رقم ^ץ لسنة Y I I بشأن مجلس الشعب المعدل بالقانون رقم 1/11 لسنة 1917 فيما تضمنه من النص على ان يكون لكل دائرة عضو واحد يتم انتخابه عن طريق الانتخاب الفردي ، ويكون انتخاب باقي الاعضاء الممثلين للدائرة عن طريق الانتخاب بالقوائم الحزبية ، ولما كانت 
انتخابات بجلس الشعب قد اجريت بناءً على نص المادة التي ثبت عدم دستوريتها بالحكم الذي انتهت اليه المحكمة في الدعوى المماثلة ، فان مؤدى هذا الحلكم ولازمه ان تكوين المجلس المذكور يكون باطلاً منذ انتخابه، الا ان هذا البطلان لا يؤدي البتة الى ما ذهب اليه المدعي من وقوع انهيار دستوري ، و لا يستبع اسقاط ما اقره المجلس من قوانين وقرار ات وما اتخذه من اجراءات خلال الفترة السابقة وحتى تاريخ نشر هذا الحكم في الجريدة الرسمية ، بل تضل القوانين والقرارات والاجراءات محمولة على اصلها من الصحة ، ومن ثم تبقى صحيحة ونافذه مالم يتقرر الغاءها او تعديلها من الجهة المختصة دستورياً او يقضى بعدم دستورية نصو صها التشريعية ان كان لذلك ثمة وجه اخر غير ما بني عليه هذا الحكم) .

المطلب الثالث: مبررات نظرية الموظف الفعلي لم تخرج نظرية الموظف الفعلي عن ضو ابط مبدأ الشرعية ـ وانما طبتتها بصورتها المثلى التي يجب ان تطبق فيها.

\section{الثفرع الأول : مبـدأ العدالة}

من العدل حماية الحقوق والمراكز القانونية التي تتقرر بموجب قواعد القانون وبإجراءات سليمة ـ ولكن يتبين فيما بعد ان الموظف الذي اصدر القرار ـ كان قرار تعيينه او منحه الصلاحية مشوباً بعيب يجعله باطلاً وقضي بإلغائه . فما العلاقة بين الحالتين لا سيا وان صاحب الحق حسن النية ولم يكن يعلم بذلك .

\section{الفرع الثاني: مصلحة المجتمهح}

ان مصلحة المجتمع تقتضي ان يثق الناس بأجهزة الدولة ـ ويرتبون اوضاعهم على ما تصدره من قرارات وفق الاجراءات المعتمدة لديها ـ فليس من المنطقي والمقبول عقلاً ان نكلف الناس بالتقصي عن صحة قرار تعيين او ترقية الموظفين العامين الذين يتعاملون معهم قبل ان يبدؤ بالتعامل الفعلي (13)، والقول بغير ذلك ينزع الثقة بأجهزة الدولة وهو امر غير مقبول ـ ويؤدي الى نتائج خطيرة فمثلاً: لو تم سحب قرار صادر بالترخيص لفتح صيدلية لان من اصدره لم يكن يملك صلاحية ذلك ـ فمعنى ذلك ان كل العلاقات التي نشأت بين المرخص له وعملائه تكون باطلة وهو امر لا يمكن قبوله ـ ولذلك فان سحب قرار الترخيص وفقا هذه النظرية يجفظ 
مصالح الناس وتبقى العلاقات سليمة بين المتعاقدين وفقا للمبادئ العامة للقانون. وهذا الامر ينطبق فيا يتعلق بقرار سحب الاعتراف بالشخصية المعنوية. فان ذلك لا يؤثر على ما نشأ من علاقات بين الشخص المعنوي وبين الغير، بل تبقى سليمة. وتصفى تبعاً للقواعد المقررة بهذا الشأن، وطبقا للمبادئ العامة للقانون(14). فلو قيل بالأثر الرجعي في الامثلة السابقة ، لأدى ذلك الى انهيار المركز القانوني للأفراد حسني النية ـ و الذي من شأنه ان يحدث فوضى واضطراب في سير المرافق العامة ـ فمثلاً لو الغي او سحب قرار تعيين موظف بمصلحة التوثيق لعدم مشروعيته ـ فمعنى ذلك بطلان كل العقود والمحررات التي تم توثيقها على يده ـ وهو امر لا يمكن قبوله عقلاً. لذلك من المصلحة العامة ومصلحة الثقة بها تبرمه الاجهزة الرسمية من عقود ومحررات ان تبقى الاعهال الصادرة من الموظف صحيحة طالما كانت مطابقة لحكم القانون .

\section{لا يجوز كلإدارة أن تستفيد من تطبيق هذه النظرية ؟} لم يجز بجلس الدولة الفرنسي لجهة الادارة الاستناد لهذه النظرية لصالحها وتبعه في ذلك القضاء المصري ـ لأنها وجدت لحماية الافراد حسني النية من اخطاء ليس لفم يد فيها وانها تعود للإدارة . واستناداً على ذلك فاذا كانت التصرفات الصادرة من الموظف الفعلي ـ من شأنها ان ترتب التزامات في مواجهة الافراد فإنها تعد باطلة ولا يترتب عليها اي اثر قانوني (15). وقد ميز البعض(16) بين الاعمال التي قام بها الموظف الفعلي وجرى تنفيذها قبل اعلان صحيفة دعوى الالغاء، وبين الاعحال التي صدرت قبل دعوى الالغاء ولم تنفذ الا بعدها. فالأولى : لاشك حول سلامتها ـ اما الثانية: فان للأفر اد الحق في التمسك بها دون ان يكون ذلك للإدارة ـ و السبب ان الافر اد في الغالب لا يعلمون بوجود الطعن، وحتى لو علموا فلا يمكنهم التنبؤ بنتائجه. اما الادارة فإنها تعلم بالطعن، ولها من المقدرة ما يمكنها من تقدير مدى جديته . فان هي قامت بتنفيذ العمل رغم ما ظهر هلا من عيب في قرار تعيين الموظف . فإنها تتحمل مسؤولية خطأها . 
وهذا الرأي يحمي الافراد من جهة ، ويحمل الادارة مسؤولية خطئها من جهة اخرى(17).

\section{المطلب الرابع: علاج عودة من نحي عن وظيفته بقرار غير مشروع} قد يحصل ان يفصل الموظف او يعزل من الوظيفة او يهال المى التقاعد . ولكن بسبب عيب في قرار العزل او الفصل او الاحالة على التقاعد ـ يسحب او يلغى القرار الاول ويصدر قرار اخر يقضي بعودته المى وظيفته. ومقتضى قرار سحب او الغاء قرار الفصل او العزل او الاحالة على التقاعد ، ان يعود الموظف المى وظيفته التي كان يشغلها قبل صدور القرار الملغي او المسحوب ـ ولكن قد يجصل وهو المعتاد، ان يتم تعيين من يخلفه في شغل الوظيفة ـ ولذلك فان اعادته اليها تتعارض مع حق مكتسب للغير الذي حل محله ـ وقد عالج بجلسا الدولة في فرنسا ومصر هذا الموضوع في العديد من الاحكام وكذلك القضاء الاداري في العراق .

\section{الفرع الأول : موقف مجلس الدولة الفرنسي}

لقد قضى بجلس الدولة الفرنسي في اول احكامه في VV - هـ - 9 ـ | (18)، بعودة الموظف الذي سحب قرار انهاء خدمته الى وظيفته التي كان يشغلها ، وان يتم سحب قرار تعيين خلفه. إلا انه في قضائه اللاحق عدل عن هذا المبدأ متى تعذرت عودته الم نفس وظيفته التي كان يشغلها ، وانها قرر عودته المى وظيفة اخرى مماثلة ها وبنفس فئتها تفاديا للمساوئ التي تحدث لو تم التشدد بالعودة الى نفس وظيفته ـ لاسيها في حق الموظف

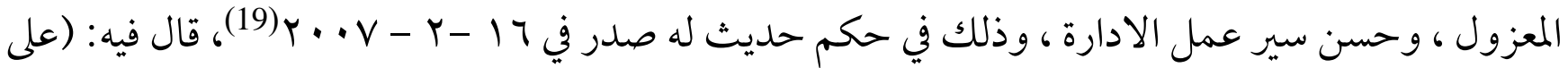
الادارة ان تعيد العامل المى وظيفته التي كان يشغلها، فان تعذر ذلك تتم عودته الى وظيفة مماثلة لوظيفته التي كان يشغلها موازية لها في الواقع). ومع ذلك فقد قرر المجلس عودة الموظف المى ذات الوظيفة التي كان يشغلها في حالات ثلاث هي: 1 - حالة انهاء الخدمة لجميع الموظفين بصفة عامة ولم تجد الادارة في مدة معقولة اية وظيفة خالية مطابقة للتي كان الوظف يشغلها قبل عزله فعندئذ يجب عودته الم نفس الوظيفة التي كان يشغلها. وذلك بعد سحب قرار تعيين الموظف الذي تم تعيينه ححله على وجه غير مشروع(20). 
2 - حالة الغاء قرارات انهاء الخدمة بالنسبة للقضاة بسبب قاعدة عدم قابليتهم للعزل(21). 3 - حالة الغاء قرارات انهاء الخدمة بالنسبة للموظفين الشاغلين لوظائف فريدة، كإلغاء قرار انهاء خدمة السكرتير العام لغرفة المهن والحرف(22).

\section{الفرع الثاني: موقف مجلس الدولة المصري}

الاتجاه العام لمجلس الدولة المصري هو عودة الموظف المسحوب قرار ابعاده عن الخدمة او المحكوم بإلغائه الى مونى نفس وظيفته التي كان يشغلها قبل قرار الابعاد مالم يعين فيها موظف اخر . وعندئذ يعود الموظف المفصول الى وظيفة اخرى مماثلة ، وليس له الحق بالتمسك بعودته المى نفس الوظيفة التي كان يشغلها طالما كان تعيين الخلف قد صدر موافقا لصحيح القانون(23). الا ان المحكمة الادارية العليا قررت اعمال الاثر الرجعي لحكم الالغاء عندما يتعلق الحكم بإنهاء الخدمة في الوظائف الوحيدة بموجب حكمها الصادر في r- 1 - بهو الذي قررت بموجبه(24) (اذ اصدر قرار بإبعاد نائب رئيس احدى الجامعات من وظائف الحكم المحلي فانه يترتب على الغاء هذين القرارين ، أن يعاد الطاعن الى الوظيفة التي كان يشغلها قبل صدور القرارين وللمدة التي حددت بقرار تعيينه فيها وهي اربع سنوات وان هذه المدة هي مدة فعلية وليست حكمية ، فيتعين ان يقضيها المحكوم له كاملة). اما ماعدا ذلك من الوظائف الاخرى، فيحق له العودة الى وظيفته التي كان عليها مالم تكن قد شغلت بموظف اخر ، فان شغلت فلا يجوز له التمسك بها وانما يعاد الى وظيفة اخرى مماثلة لها(25.

\section{الفرع الثالث: موقف القضاء العراقي}

لم يكن نهج القضاء الاداري في العراق يختلف عن نهج القضاءين الفرنسي والمصري وهو عودة الموظف المسحوب او الملغي قرار فصله او عزله الى وظيفته التي كان يشغلها قبل صدور قرار الفصل او العزل. وفيما يلي نهاذج من احكام القضاء الاداري في العراق: 
قال بجلس الانضباط (محكمة قضاء الموظفين حاليا) في حكم له بتاريخ ع - - - 997 ا : (ويجد المجلس ان عقوبة العزل شديدة جداً ، ولم يسبق للمعترض ان عوقب بأية عقوبة من عقوبات الفصل او ظهر في سيرته الذاتية ارتكاب افعال خطيرة تجعل بقاءه في الخدمة العامة مصدر ضرر او تهديد للمصلحة العامة، وانما وجد في اضبارته الشخصية عدد و افر من التشكرات والتقديرات مما يشفع له ذلك. وحيث ان القرار المطعون فيه قد صدر خلافاً لما تقدم فعليه قرر تخفيض عقوبة العزل المى التوبيخ وهي العقوبة المتناسبة مع الفعل المرتكب التي اوصى بها المستشار التربوي في الوزارة واعادة المعترض الى وظيفته السابقة)(26). وفي قرار اخر صدر في اس-Y | - 99 | يقول المجلس (27): (ان عقوبة التوبيخ متناسبة مع الفعل ، خاصة وان الموظف اخلي سبيله وافرج عنه وسدد مبلغ الهدر من انتاجية السيارة وبالسعر التجاري، وان المدعي العام طلب الغاء عقوبة العزل والابقاء على عقوبة التوبيخ، وعليه قرر الغاء امر عزل المدعي المعترض من الوظيفة والزام دائرة المدعى عليه بإعادته المى وظيفته). وفي قرار اخر صدر بتاريخ 0 - - 199V - 19قول المجلس(28): (وحيث وجد المجلس ان ما اتخذ ضد المعترض يشكل سلسلة من الاجراءات التعسفية التي تحفي تحتها عقوبات متعددة ذات اقنعة ليس لها وجود، قرر الغاء التهمة والافراج عن المعترض واعادته المى مركزه الوظيفي). وفي قرار صدر في 1-0- ع991 يقول المجلس (29): (وحيث ان فعل الموظف هو تأخر عن الدوام بسبب ظروف النقل والسكن ، كما اوضحته المر افعة الجارية ، كما ان اضبارة المدعي وسيرته الذاتية لم يؤشر فيها على المدعي عقوبات تبيح للإدارة فصل الموظف او عزله لان الفصل والعزل حالات محددة ، ولم يكن من بينها تقاعس الموظف عن اداء عمله ، لذا يكون القرار المطعون به مشوبا بعيب خرق القانون ، لان ما نسب الى المدعي لا يوجب العزل او الفصل من الوظيفة ، وبذلك تكون الجهة الادارية متعسفة في قرار الفصل المطعون فيه ، لذا قرر الغاءه واعادة المدعي المى وظيفته وقبول مباشرته فيها). 


\section{المطلب الخامس: تطبيق النظرية على السلطة ِِف عراق ما بعد الاحتلال}

\section{مدى مشروعية احتلال العراق:}

يقول رئيس امريكا الحالي ترامب: (ان غزو العراق كان اسوأ قرار في تاريخ امريكا)، وقبله صدرت تصريحات لمسؤولين دوليين تصف غزو العراق بانه خارج قواعد الشرعية الدولية. سواء من حيث مبرراته التي ثبت انها كانت كاذبة ولا صحة لما. واهدافه التي زعموا فيها انهم سيجعلونه نموذجا للديمقراطية ، فتبين انه اسوأ نموذج للتدمير الذي رجع بالعالم المى القرون الوسطى وهو حكم القوة التي لا تعرف الانسانية . فقد اعتبروا العراق كله غنيمة حرب يتقاسمونها فيها بين المساهمين في غزوه ـ دون اي اعتبارات لشرعية حقوق الانسان و المو اثيق الدولية . وعليه فان سلطة الاحتلال قد اباحت لنفسها الغاء كل مظاهر الدولة. واعادة بنائها وفق اهوائها دون الالتفات الى قو اعد القانون الدولي ـ التي تحظر على قوات الاحتلال اصدار اي تشريعات ادارية ، او اجراء اي تغييرات هيكلية او اجراء اي استفتاء ـ ولكن سلطة الاحتلال خالفت كل ذلك ، فقامت بحل مؤسسات الدولة العسكرية والامنية والمدنية ، وقد فشلت في بناء مؤسسات بديلة ـ فدخل العراق تحت سلطة المليشيات التي تعمل لمصلحة كل طالب ثأر منه ـ ولهذا فإنها كثيرة ومتنوعة ـ وساد الفساد الاداري والمالي بشكل غير مسبوق، فكل مليشيا او جهة سياسية تعمل لمصلحتها، حتى اصبح المواطن يبحث عن وطن كما عبر عنه المتظاهرون الذين يو اجهون كل انواع القمع الهمجي من جهات مجهولة . لذلك يمكن للباحث القول بعدم وجود حكومة مشروعة تقر بمسؤوليتها عن حماية حقوق المو اطنين وامنهم . تجاه عصابات مسلحة تحكم قبضتها على كل مفاصل الدولة . وعليه فان القرارات التي صدرت منذ التاسع من نيسان عام ب . ץ ـ دون تمييز بين تلك التي اصدرها الحاكم المدني الامريكي او التي صدرت بعد ذلك من سلطة الامر الواقع التي تم تشكيلها بموجب دستور ه •. r الذي تم تمريره بالتزوير • وكل الانتخابات التي جرت في ظله كانت مزورة ـ وعليه يمكن تقسيم قرارات سلطة الامر الو اقع في العراق الى فئين ، اما قرارات منعدمة ، واما قرارات باطلة حتى يثبت القضاء صحتها . 


\section{الفرع الأول : فئة القرارات المنعمدمة}

الانعدام يعني ان القرار ولد ميتا ولذلك لا يمكن ان ينتج اية اثار ترتب حقوق او التزامات. ويعد القرار منعدما اذا تخلف فيه ركن اساس من اركان التصرف القانوني الذي لاوجود له من دونه وهي: الارادة، والمحل، و السبب. ويتحقق ايضا في حالة عيب عدم الاختصاص الجميم (اغتصاب السلطة) فيتجرد القرار من صفته الادارية ويترتب عليه ما يأتي: 1 - يتحول الى بجرد عمل مادي لا يرتب اي اثر قانوني ـ ومن حق الافر اد التخلص منه بو صفه عقبة مادية. 2- ييجوز سحبه اداريا دون التقيد بمواعيد الطعن • ولا يمكن تصحيحه بالإجازة اللاحقة او التأييد . 3- يعد تنفيذه من اعحال الاعتداء المادي ـ ويرتب مسؤولية جزائية لمن ينفذه ويختص القضاء العادي بنظر

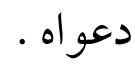
و الامثلة على ذلك في عراق ما بعد الاحتلال: 1 - قرارات حل اجهزة الدولة الصادرة من الحاكم المدني لمخالفتها لقواعد القانون الدولي المتعلقة بعمل سلطة الاحتلال في البلاد الو اقعة تحته . 2- قرارات تنحية الموظفين تحت ذريعة اجتثاث البعث ، ويحق لهم ولورثة من مات منهم الطعن فيها امام المحاكم العادية واعادة حقوقهم وفقا للقانون. لان الغاية من ذلك هي الاستيلاء على العناوين الوظيفية وتوزيعها على الاحز اب القادمة مع الاحتلال . الاحل. 3 - كل القرارات المتعلقة بإنشاء الاجهزة والدوائر المستحدثة بعد الاحتلال والتي كانت باباً كبيراً من ابواب الفساد الاداري والمالي .لان هدفها نهب المال العام على شكل رواتب وخصصات وغير ذلك لأعضاء الاحزاب وليس تحقيق المصلحة العامة. 4 - الرواتب والمخصصات وغيرها من المسميات التي تم نهب المال العام بواسطتها لأعضاء بجلس الحكم ولرئيس الجمهورية ولرئيس مجلس النواب ولرئيس بجلس الوزراء ونوابهم ومستشاريهم وموظفي 
دوائرهم والرواتب والمخصصات الممنوحة للوزراء والنواب ولأفراد حماياتهم وسواها من المنافع

المختلفة.

5 - قرارات منح افراد عاديين رواتب خاصة لهم ولأسرهم · كرواتب رفحاء ورواتب الانصار والبيشمركة ،

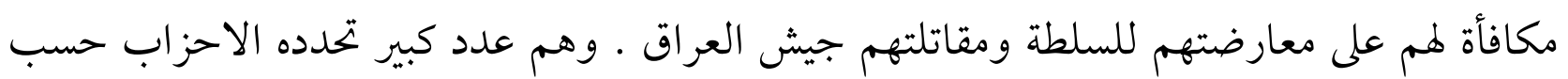
اهو ائها ، وهذه تشكل رافدا كبيرا من روافد استنزاف المال العام.

6 - قرارات صرف الرواتب لأشخاص وهميين لا وجود لهم وهو باب من ابو اب نهب المال العام.

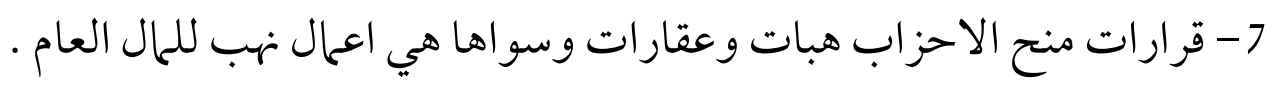

8 - استغلال المو انئ والمنافذ الحدودية وجعلها تحت سيطرة الاحزاب ولجانها الاقتصادية ـ ومزاد بيع العملة وغير ذلك من ابواب نهب المال العام كلها اعمال اعتداء مادي على الدولة .

وبصورة عامة كل قرار تعيين او استحداث دائرة او منصب او عنوان وظيفي او صرف مال عام ليس فيه مصلحة بل ادى الى مفسدة صدر بعد الاحتلال ، يعد منعدما وتطبق بشأنه القواعد الخاصة بالقرار المنعدم

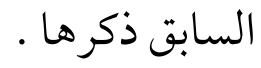

\section{الفرع الثاني: فئة القرارات الباطلة}

وهي القرارات التي تمليها ضرورة تسيير المرافق العامة والقرارات المتعلقة بحفظ النظام العام بعناصره الاربع وهي : الامن العام ، والصحة العامة ، والسكينة العامة ، والآداب العامة . ولكون السلطة هي سلطة الامر الواقع التي نشأت من رحم الاحتلال فان قراراتها تكتسب من مشروعية الاهداف منها ، ومن مشروعية الاجراءات المحددة قانونا. وهذه قابلة للطعن بصحتها من كل صاحب مصلحة.

ولكون العراق تحت ظرف استثنائي منذ ب . ب و والى يومنا هذا وان طرق الطعن بالقرارات غير متاحة وان المو اطن لا يأمن البطش والانتقام عندما يطعن بها فضلا عن عدم ثقته بالدولة واجهزتها فان مدد الطعن المحددة في القانون تتوقف لحين زوال الظرف الاستثنائي وتبقى مفتوحة المى حين قيام سلطة شرعية ـ وعندئذ 
يمق لكل من لحقه اذى ان يطعن بها لاسترجاع حقه ، فيكون الاختصاص حينئٍ للقضاء الاداري وللقضاء العادي • ويختص القضاء الاداري بالطعن في القرارات الصادرة من الموظفين في دوائر الدولة والقطاع العام بوصفهم موظفين فعليين ـ تابعين لسلطة الامر الواقع المنصبة من قبل قوة غازية ـ وان يراعي القضاء ماية حسني النية ، ومصلحة تسيير المرافق العامة في الظرف الاستثنئي فيما يصدره من قرارات . فما وافق منها المصلحة المشروعة للمواطن واتبعت فيه الاجراءات المشروعة يعتبر صحيحاً. وما خالف القانون يعد باطلاً ويسأل عنه الموظف الذي اصدره ـ وهذا ينطبق على القرارات الضرورية لسير المرافق العامة بانتظام واطر اد ، وقرارات الضبط الاداري العام والخاص. ويختص القضاء العادي بكافة الدعاوي الأخرى المتعلقة بها اصاب المو اطنين من ضرر جر اء تصرفات سلطة الأمر الواقع ·

النتائج والتوصيات: النتائج:

لقد كان العراق ضحية احتلال .خرق كل قواعد الشرعية الدولية ـ وقواعد الشرعية الداخلية في تعامله مع المواطنين وحقوقهم. وفشل خلال سبعة عشر سنة في تأسيس سلطة حقيقية تحترم إرادة شعبها وتصون حقوقه. حتى اصبح الفساد الاداري والمالي هو الاسلوب الذي تسير الدولة بموجبه. وبذلك تفقد السلطة سبب وجودها وتتحول الى داء بدلاً من ان تكون دواء .

\section{التوصيات:}

ان البحث محصور في اطار قواعد القانون الاداري. فنوصي بتطبيق قواعد المشروعية على كل الاعمال التي قامت بها سلطة الامر الو اقع. فان كانت تستهدف المصلحة العامة. واتبعت فيها الاجراءات القانونية السليمة فإنها تكون جائزة. تطبيقاً لنظرية الموظف الفعلي. وان استهدفت تحقيق مصالح غير مشروعة فإنها تعتبر منعدمة وتزول باثر رجعي ولا ترتب اي اثر . وهذا ينطبق على ما صدر بتشريعات او بقرارات ادارية . 
ويكق للإفر اد وللهيئات الطعن بكل التشريعات والقرارات الصادرة منذ عام ب +. r والى حين زوال سلطة الامر الواقع .ووجود سلطة تمثل ارادة الشعب الذي يبحث عن هوية ووطن.

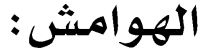

$$
\begin{aligned}
& \text { (1) الشاعر. د.رمزي ، تدرج البطلان في القرارات الادارية ، دار النهضة العربية } 1968 \text { ، ص } 365 \text { ـ. }
\end{aligned}
$$

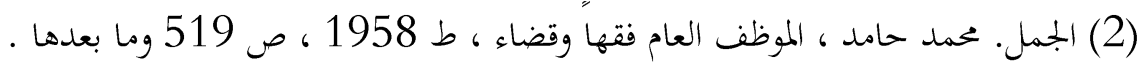

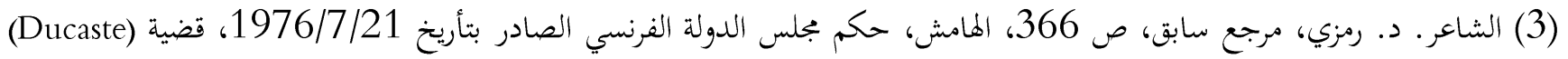

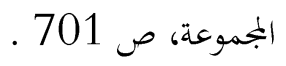

(4) الطعن رقم 1713 / 7 ق عليا الجلسة 1964/6/28 ، مجموعة احكامها في عشر سنوات رقم 665 ص ص 695 ص 695 ، وانظر حكمها

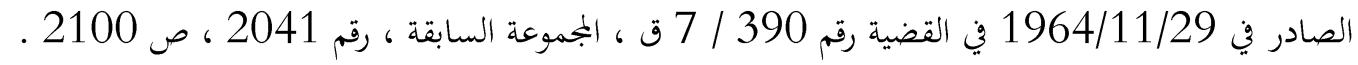

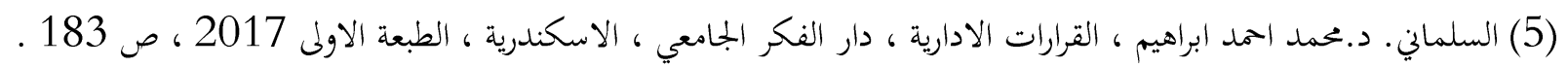

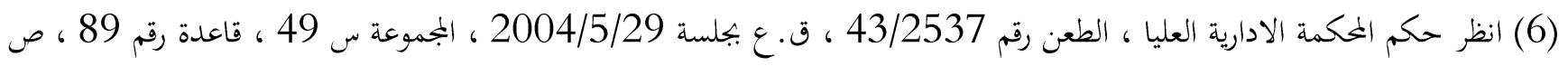
.710

Vior : CE 20-2-1957, no 3. 528, Rec p.831. (7) Vior : CE 12-12-2007 sire A.J.D.A 2008 - p.633 . (8)

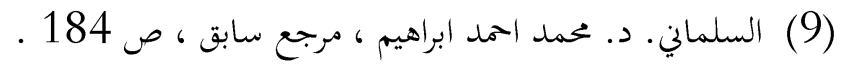

(10) الحلو. ماجد راغب ، نظرية الظاهرة في القانون الاداري ، مجلة الحقوق والشريعة ، جامعة الكويت ، السنة الرابعة ، كانون الثاني

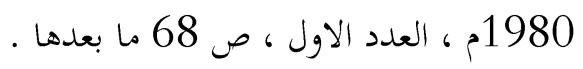

Vior : Chapus (R) droit Contenieux adam 1982 . p . 453 . (11)

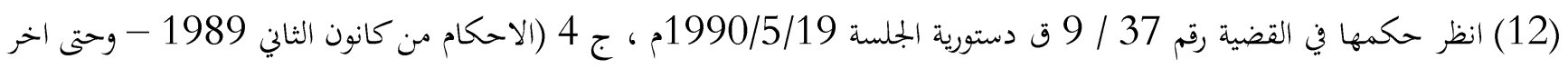

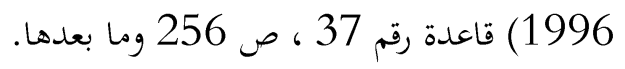

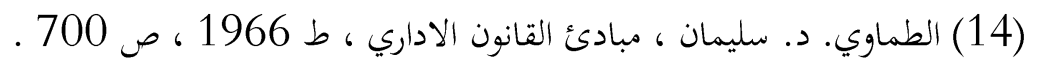

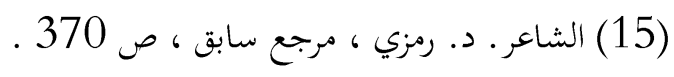

Spach : Op . Cit . p . 135-138 (16)

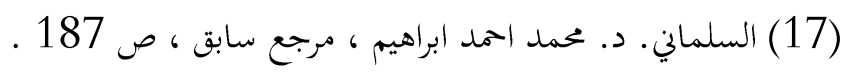

Vior : CE . 27-5-1949. Rec . p.848 . S . 1949-3-81 . (18)

Vior : CE : 16-2-2007, no 282032 Cordier, Rec : p . 91 . (19)

CE : 27-5-1949 Veron Reville Op cit , p . 246 . (20) 
CE : 8-4-2009 no 289314 chanber des métiers et de 1 arti sanat de la Mosello . A.J.D.A 2009 p.822 . (21)

Vior : CE : 16-10-1959 Guillete Rec p. 516 . (22)

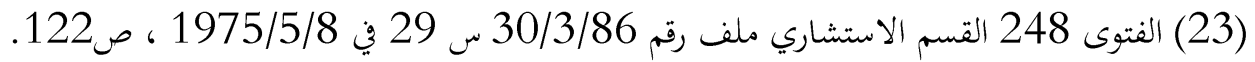

$$
\begin{aligned}
& \text { (24) حكمها في الطعن رقم 37/3258 ق . ع بجلسة 1993/8/3 . } \\
& \text { (25) الفتوى رقم } 46 \text { في 1980/1/19 جلسة 1979/12/12 ، مجلد (34) ، قاعدة رقم (45) ، ص ص } 79 \text { ـ }
\end{aligned}
$$

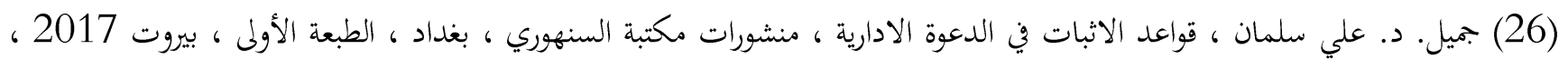

$$
\text { ص } 264 \text { ، رقم القرار 1996/31 ، رقم الاضبارة 1995/35 . }
$$

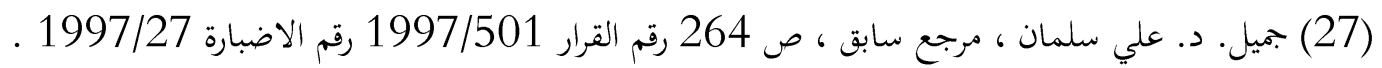

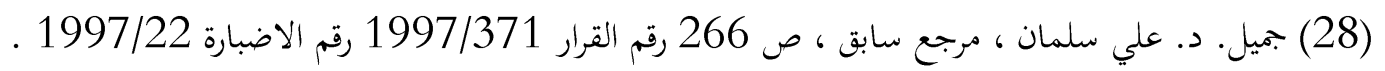

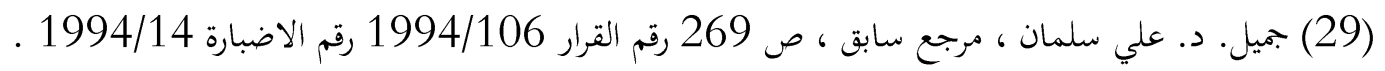

